\title{
Creating an Effective Fact Sheet
}

act Sheets are a powerful
way for USGS scientists to
rapidly communicate the results
of their work directly to the pub-
lic. These concise official publi-
cations can be particularly use-
ful in helping readers under-
stand and live with natural haz-
ards. Fact Sheets also increase
public awareness of the USGS'
role. Careful review and edit are
especially important with Fact
Sheets because they often touch
on sensitive issues and must
present a clear, unambiguous
message to the general public.

The mission of the U.S. Geological Survey (USGS) is to provide the Nation unbiased scientific information about our restless and environmentally fragile planet. The results of USGS work are used by policymakers, private industry, and the general public. Because of their technical nature, however, many USGS publications do not convey a clear message to the non-scientist.

Fact Sheets, an official publication series of the USGS since 1994, are proving effective in fulfilling this important part of our mission. For example, these concise publications can be powerful tools for directly alerting the public to natural hazards-enabling readers to better prepare themselves and also allaying unwarranted fears.

As with other USGS publication series, Fact Sheets must go through the official approval process, including review, editing, and Director's approval. Because they often touch on sensitive issues and must present a clear, unambiguous message to the public, a thorough process of review and editing is especially important for Fact Sheets.

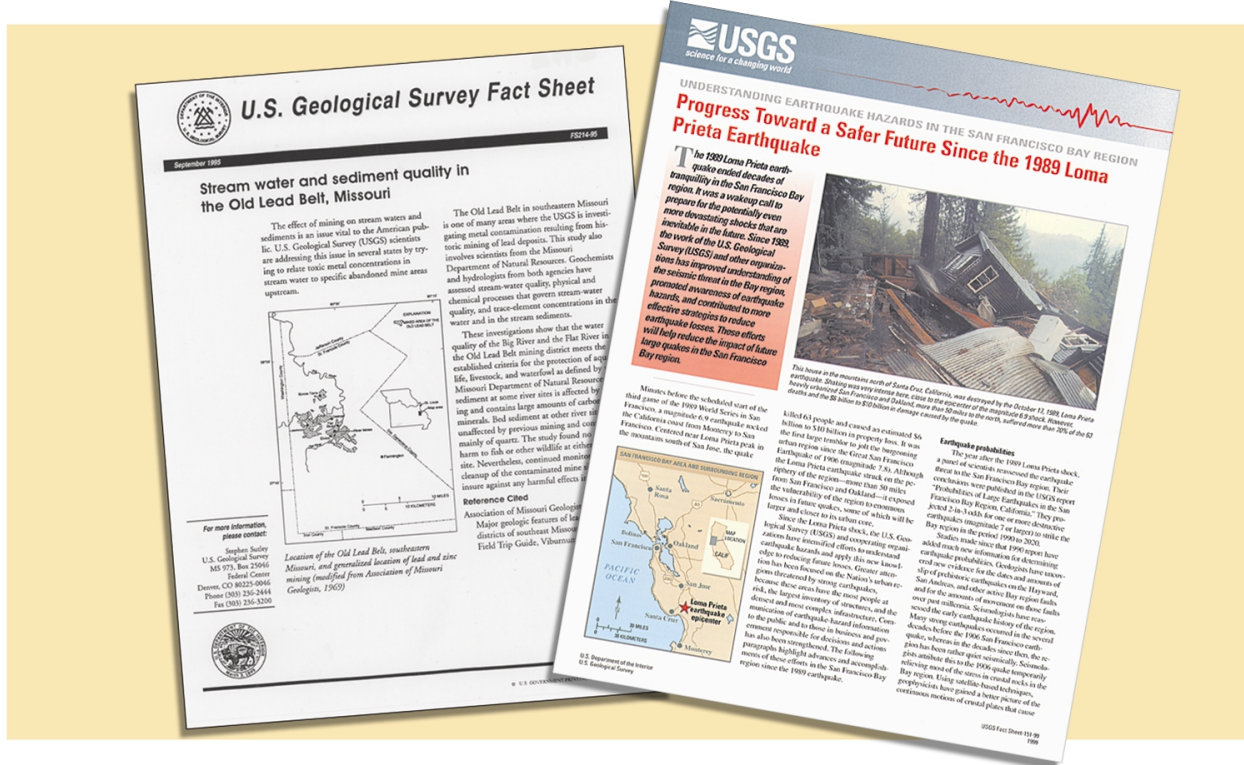

No matter how well written, a Fact Sheet will not convey its message unless it is picked up and read. In publications intended for a general audience, the importance of color and format cannot be overstated. An attractively formatted, color Fact Sheet with a striking illustration on the first page is far more likely to be picked up and read by a member of the public than is a plainer looking black-and-white product. Colorful illustrations, an interesting format, and a bold, active title help capture the viewer's attention at a quick glance.

\section{Essential Elements of a Good Fact Sheet}

- Good science

- Short, active, and non-technical title

- Brief abstract

- Attention-grabbing introduction (usually a story)

- Clear, concise message that readers can relate to

- Well-explained benefit to society

- Point of contact for more information

- Eye-catching, effective graphics

- Format that identifies it as a USGS product

\section{What Authors Need To Provide}

- DRAFT TEXT (No more than 1,500 words for a 2-page Fact Sheet; 2,500 words for a 4-page Fact Sheet)—Initially, authors should not worry too much about length or the use of technical terms; culling a more detailed text and rewording it for the general public is easier than filling gaps in an incomplete text. Editors can greatly assist authors by doing substantial rewriting and can help craft an attention-grabbing introduction.

- GRAPHIC MATERIAL - Illustrations may include photographs (those showing people actively working are particularly good), small maps, technical diagrams, and sketches. Editors and graphic artists can help produce easily understood graphics from technical illustrations or even from rough ideas or sketches.

- CONSULTATION-Frequent consultation is required between authors, editors, and graphic artists. An effective Fact Sheet is usually the product of extensive interaction and feedback.

\section{About the Process}

- REVISE! REVISE! REVISE! -Expect the text, captions, and illustrations to go through many successive versions, bouncing back and forth among editors, authors, graphic artists, and reviewers. Much of the writing, editing, reviewing, and "polishing" occurs concurrently. Captions often reach final form last, after the graphics are completed.

- TEAMWORK - Every phrase in a Fact Sheet must be carefully considered to ensure that it can be clearly understood, cannot be misread, and conveys no unintended meanings to the non-technical reader. Experience has shown that the synergy of people working together not 


\section{SYNERGY FUELS THE CREATION OF EFFECTIVE FACT SHEETS}

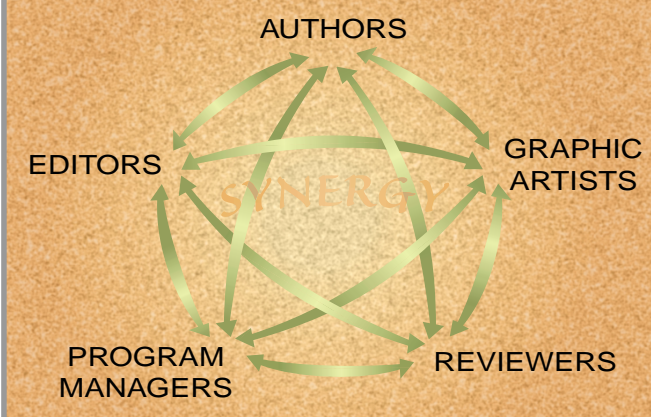

only results in higher quality but also saves time. For example, a team of two editors rewriting and "polishing" the text of a Fact Sheet at the same computer monitor has proved more time-effective than a single editor working alone. Roundtable discussions between the authors, editors, and graphic artists are also very productive.

- REVIEW \& TEST MARKETING-Different eyes see different things, so you almost cannot have too many people read and review a Fact Sheet. For example, each of the 13 Fact Sheets in the series Reducing Earthquake Losses Throughout the United States (produced in 1995 and 1996) was routinely reviewed several times by 7 to 11 people, including editors, graphic artists, authors, series coordinators, and the Publications Group Chief. All of them found some way to improve each Fact Sheet. In addition, many of the Fact Sheets were reviewed by non-scientists outside the USGS (often family members); the comments of these "test readers" from the general public often also resulted in significant improvements.

\section{General Tips}

- COLOR! COLOR! COLOR! - Tasteful and effective use of color makes it more likely that the general public will pick up a publication and read it. Some black-andwhite images can be successfully incorporated, but usually color is the attractant.

- BANNER HEAD_A series banner head above the Fact Sheet's title is a good way to tell the reader the general subject area being discussed. Future related Fact Sheets can then be placed in the same series.

- "SPEAK PLAINLY"-Because Fact Sheets intended for the public must be easily understood by a broad audience, text should be written for a high-school ("National Geographic") reading level.
Technical terms should be used only if absolutely essential to convey the meaning, and any technical term used must be explained clearly.

- CONCISENESS - The final abstract of a Fact Sheet should be about 70 words long. The final text (excluding captions) for a 2page Fact Sheet should be about 1,000 words (2,000 words for a 4-page Fact Sheet). To achieve the required conciseness, eliminate anything that is not necessary. As you read the information contained in the text, ask yourself, "Will the public really care about this?" If the answer is "No," either delete the particular item or, if it is essential to the story, make it relevant. Subheadings and bullet items are not generally used (because they require extra space) but may be appropriate for some topics, as with this Fact Sheet.

- ABSTRACT \& CAPTIONS-Because some people will only read the abstract and captions and look at the illustrations, these elements should carry the essentials of the message contained in the Fact Sheet. Captions may therefore purposely repeat portions of the text, sometimes verbatim. - COOPERATORS - When appropriate, non-USGS organizations and groups in-
Creating an effective Fact Sheet for the general public involves many revisions and much teamwork. Every aspect of a Fact Sheet must be carefully considered to ensure that it will be clearly understood by the non-scientist reader. Roundtable discussions and bouncing successive revisions among team members produces a synergy that not only results in higher quality but also saves time.

volved in the work discussed in the Fact Sheet can be listed under "Cooperating Organizations," usually following the names of authors and graphic designers.

- POINT OF CONTACT-So that the interested reader can get more information on the topic presented, a point of contact should be given at the end of each Fact Sheet. Include a telephone number, mailing address, and e-mail and (or) website address. Because people's assignments change, it is best not to give a person's name as the point of contact. An 800 telephone number is best, and the caller should be able to talk to someone immediately or leave a message that will receive a prompt response. If appropriate, reference can be made to related Fact Sheets.

Fact Sheets created through the intensive review and editing process outlined here are already reaching a broad audience. Public demand has been so high for these products that many have been reprinted within months of publication, even with initial printings of 10,000 copies each. By using effective products such as these Fact Sheets, USGS scientists can bring the benefits of their work more directly to the citizens of our Nation.

Peter H. Stauffer and James W. Hendley II Graphic design by Susan Mayfield and Sara Boore

For more information contact:

Western Publications Group (650) 329-5038

U.S. Geological Survey, Mail Stop 951

345 Middlefield Road, Menlo Park, CA 94025 http://geopubs.wr.usgs.gov

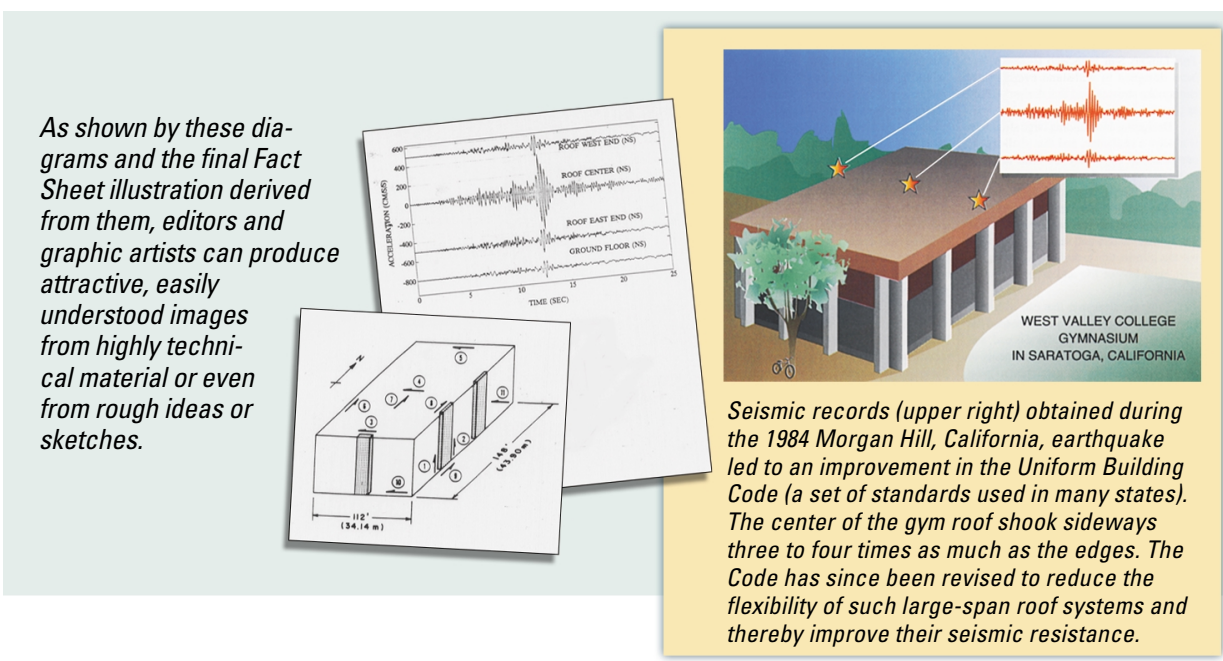

